OPEN ACCESS

Edited by: Grazia Rutigliano, University of Pisa, Italy

Reviewed by: Domenico Tricò University of Pisa, Italy Zhiqiang Li,

Qingdao University, China

*Correspondence: Javier Labad jlabad@tauli.cat

Specialty section: This article was submitted to Schizophrenia, a section of the journal

Frontiers in Psychiatry

Received: 25 February 2020 Accepted: 05 May 2020 Published: 25 May 2020

Citation: Montalvo I, González-Rodríguez A, Cabezas Á, Gutiérrez-Zotes A, Solé M,

Algora MJ, Ortega L, Martorell L,

Sánchez-Gistau V, Vilella E and Labad J (2020) Glycated Haemoglobin Is Associated With Poorer Cognitive Performance in Patients With Recent-Onset Psychosis. Front. Psychiatry 11:455. doi: 10.3389/fpsyt.2020.00455

\section{Glycated Haemoglobin Is Associated With Poorer Cognitive Performance in Patients With Recent-Onset Psychosis}

\author{
Itziar Montalvo ${ }^{1}$, Alexandre González-Rodríguez ${ }^{1}$, Ángel Cabezas ${ }^{2}$, \\ Alfonso Gutiérrez-Zotes ${ }^{2}$, Montse Solée ${ }^{2}$, Maria José Algora ${ }^{2}$, Laura Ortega ${ }^{3}$, \\ Lourdes Martorell ${ }^{2}$, Vanessa Sánchez-Gistau ${ }^{2}$, Elisabet Vilella ${ }^{2}$ and Javier Labad ${ }^{1 *}$ \\ ${ }^{1}$ Department of Mental Health, Parc Taulí Hospital Universitari, Institut d'Investigació Sanitària Parc Taulí (I3PT), Universitat \\ Autònoma de Barcelona, CIBERSAM, Sabadell, Spain, ${ }^{2}$ Hospital Universitari Institut Pere Mata, Institut d'Investigació \\ Sanitària Pere Virgili (IISPV), Universitat Rovira i Virgili, CIBERSAM, Reus, Spain, ${ }^{3}$ Nursing Department, Universitat Rovira i \\ Vigili, Tarragona, Spain
}

Background: Glucose abnormalities and cognitive alterations are present before the onset of schizophrenia. We aimed to study whether glucose metabolism parameters are associated with cognitive functioning in recent-onset psychosis (ROP) patients while adjusting for hypothalamic-pituitary adrenal (HPA) axis measures.

Methods: Sixty ROP outpatients and 50 healthy subjects (HS) were studied. Cognitive function was assessed with the MATRICS Consensus Cognitive Battery. Glycated haemoglobin $\left(\mathrm{HbA} 1_{\mathrm{c}}\right)$, glucose, insulin, and $\mathrm{C}$-peptide levels were determined in plasma. The HOMA-insulin resistance index was calculated. Salivary samples were obtained at home on another day to assess the cortisol awakening response and cortisol levels during the day. Univariate analyses were conducted to explore the association between glucose metabolism parameters and cognitive tasks. For those parameters that were more clearly associated with the cognitive outcome, multiple linear regression analyses were conducted to adjust for covariates. Each cognitive task was considered the dependent variable. Covariates were age, sex, education level, diagnosis, antipsychotic and benzodiazepine treatment, body mass index (BMI), smoking, and HPA axis measures. Potential interactions between diagnosis and glucose parameters were tested.

Results: There were no significant differences in HPA axis measures or glucose parameters, with the exception of C-peptide (that was higher in ROP patients), between groups. ROP patients had a lower performance than HS in all cognitive tasks ( $p<0.01$ for all tasks). Of all glucose metabolism parameters, HbA1c levels were more clearly associated with cognitive impairment in cognitive tasks dealing with executive functions and visual memory in both ROP patients and HS. Multivariate analyses found a significant negative association between $\mathrm{HbA} 1 \mathrm{c}$ and cognitive functioning in five cognitive tasks dealing with executive functions, visual memory and attention/vigilance (a ROP 
diagnosis by $\mathrm{HbA} 1_{\mathrm{c}}$ negative interaction was found in this latter cognitive domain, suggesting that $\mathrm{HBA} 1_{\mathrm{C}}$ levels are associated with impaired attention only in ROP patients).

Conclusions: Our study found that $\mathrm{HbA} 1_{\mathrm{c}}$ was negatively associated with cognitive functioning in both ROP patients and HS in tasks dealing with executive functions and visual memory. In ROP patients, $\mathrm{HbA1}_{\mathrm{c}}$ was also associated with impaired attention. These results were independent of BMI and measures of HPA axis activity.

Keywords: glucose, glycated haemoglobin, cognition, early psychosis, cortisol

\section{INTRODUCTION}

Cognitive alterations are well-known predictors of social functioning in people with schizophrenia and related psychotic disorders (1). These cognitive alterations are present at early stages of the psychotic illness, even before the development of positive psychotic symptoms (delusions, hallucinations) (2). Biological mechanisms explaining these cognitive deficits are complex and include the potential role of hypothalamicpituitary-adrenal (HPA) axis hormones $(3,4)$, thyroid hormones $(5,6)$, prolactin $(7,8)$, inflammatory markers $(9,10)$ and the genetic background (11).

In our current study, we aimed to explore whether glucose metabolism parameters might contribute to the cognitive impairment of people with recent-onset psychosis (ROP). Previous studies including drug-naïve first-episode psychosis and healthy controls have reported increased glucose and insulin resistance (12) and impaired glucose tolerance (13), suggesting that glucose-related parameters may be altered in patients with psychosis at the early stages of the illness. Previous studies have also reported an increased prevalence of type 2 diabetes in the parents of people with non-affective psychosis (14). It was initially thought that this association may be due to shared environmental or genetic risk factors, or both. However, a recent study (15) exploring the association between polygenic risk score of schizophrenia and glycated haemoglobin $\left(\mathrm{HbAl}_{\mathrm{c}}\right)$ while adjusting for polygenic risk score of type 2 diabetes, and clinical and demographic covariables suggests that the mechanisms of hyperglycemia or diabetes are at least partly independent from genetic predisposition to schizophrenia.

It is also known that comorbidity with diabetes mellitus is associated with more severe cognitive deficits in schizophrenia (16). Type 2 diabetes is a risk factor for cognitive decline (17), mild cognitive impairment (18), and progression to dementia (19). Although the exact pathophysiology of mild cognitive impairment in type 2 diabetes is unclear, many studies suggest that several coexisting risk factors contribute to the cognitive impairment (20): chronic hyperglycaemia, diabetic complications (macrovascular and microvascular disease), inflammatory reaction and advanced glycation end products, and psychological status (e.g. depressive symptoms). In a systematic review (21) that included 86 studies exploring the role of glucose regulation (glycaemia, hypoglycaemic events, insulin concentration, insulin resistance, and glucose-lowering treatment) and cognitive function in people with type 2 diabetes without dementia, high $\mathrm{HbAl}_{\mathrm{c}}$ and glucose variability were negatively associated with cognitive function. $\mathrm{HbAl}_{\mathrm{c}}$ is a promising biomarker for cognitive impairment because it is also associated with poorer cognitive abilities in people without diabetes $(17,22)$. A recent study suggests that $H b A 1_{c}$ is associated to both cognitive performance and white matter integrity in healthy young adults (22).

Few studies have explored the potential relationship between glucose metabolism indices and cognitive functioning in patients with psychotic disorders. In a study conducted in first-episode drug-naïve patients with schizophrenia, glucose intolerance (measured with a $75 \mathrm{~g}$ oral glucose tolerance test) was associated with more negative symptoms and poorer social cognition, but not with poorer neurocognitive performance (23). In another study that measured $\mathrm{HbAl}_{\mathfrak{c}}$, this parameter was associated with poorer global cognition and attention in men (but not women) with schizophrenia (24). Insulin resistance has been associated with alterations in dopaminergic reward systems and homeostatic signals affecting food intake, glucose metabolism, body weight, and cognitive performance (25), being a potential moderator of the cognitive outcome in patients with psychotic disorders. Although several studies have reported an association between diabetes and cognition on schizophrenia, few investigations have explored the role of glucose parameters on cognition in patients with early psychosis.

We aimed to explore the previous hypothesis while adjusting for HPA axis measures, as some indices, such as a blunted cortisol awakening response (CAR) $(3,26,27)$ and elevated cortisol diurnal levels during the day (26), have been reported to be associated with a poorer cognitive outcome in people with ROP. Moreover, elevated glucocorticoids contribute to the cognitive impairment of patients with type 2 diabetes (28).

Taking into account that $\mathrm{HbAl}_{\mathrm{c}}$ has been associated with poorer cognitive performance in both patients with schizophrenia (24) and healthy individuals (22), we hypothesized that $\mathrm{HbAl}_{\mathrm{c}}$ would be associated with poorer cognitive performance in both people with ROP and healthy individuals. We also aimed to conduct exploratory analyses regarding the contribution of other glucose-related parameters (fasting glucose, c-peptide, insulin resistance) on poorer cognitive functioning. 


\section{METHODS}

\section{Sample}

Sixty ROP outpatients and 50 healthy subjects (HS) were studied. All patients (aged between 18 and 35 years) were attending the Early Intervention Service for Psychosis from Reus (Hospital Universitari Institut Pere Mata, Spain) had a DSM-IV diagnosis of a psychotic disorder [schizophreniform disorder $(n=14)$; schizophrenia $(n=10)$; schizoaffective disorder $(n=8)$ or a psychotic disorder not otherwise specified $(n=28)]$. All patients had a duration of illness of $<3$ years $(65 \%$ were patients with firstepisode psychosis). A control population of $50 \mathrm{HS}$ matched by sex and age was recruited from the community using advertisements. The sample of the study belongs to a project aiming to study the relationship between hormones and cognitive abilities in early psychosis. For this reason, participants of our study participated in a previous study that tested a different hypothesis focused on HPA axis hormones (3). The exclusion criteria were severe neurological disease or mental retardation; pregnancy; language difficulties; visual impairment; alcohol, heroin or cocaine dependence; or treatment with glucocorticoids.

The research protocol was approved by the Ethics Committee of Hospital Universitari Sant Joan, and all participants provided written informed consent after having received a full explanation of the study.

\section{Clinical Assessment}

All patients were interviewed by an experienced psychiatrist using the Schedules for Clinical Assessment in Neuropsychiatry (29). The OPCRIT checklist version 4.0 (available at http://sgdp.iop.kcl. ac.uk/opcrit/) was used to obtain DSM-IV diagnoses. The severity of positive, negative and general symptoms was assessed with the Positive and Negative Syndrome Scale (PANSS) $(30,31)$ to assess the severity of psychotic symptoms.

The Spanish version of the MATRICS Consensus Cognitive Battery (MCCB) was used to assess neurocognitive functioning (32), and it includes 10 cognitive tests assessing 7 cognitive domains: processing speed, attention and vigilance, working memory, verbal learning, visual learning, reasoning and problem solving, and social cognition.

Sociodemographic and clinical variables were obtained in a semi-structured interview. Substance use was recorded as the consumption of alcohol (standard units/day), tobacco (cigarettes/ day), and cannabis (joints/day). Current psychopharmacological treatment was recorded during the neuropsychological assessment, as described previously (3). The dose of antipsychotics was converted to chlorpromazine equivalents following an international consensus of antipsychotic dosing (33).

Weight, height, waist circumference, and blood pressure were assessed by physical examination. Body mass index (BMI) was calculated with the formula weight $(\mathrm{kg}) /$ height $(\mathrm{m})^{2}$.

\section{Biochemical Measures}

A fasting morning blood analysis (between 8:30 a.m. and 9:30 a.m.) was obtained by antecubital venepuncture. $H \mathrm{bA} 1_{c}$, glucose, insulin, and C-peptide were determined in plasma. The
Homeostatic Model Assessment for Insulin Resistance (HOMA-IR) index was calculated using the formula HOMA$\mathrm{IR}=[$ insulin $(\mu \mathrm{UI} / \mathrm{mL}) \times$ glucose $(\mathrm{mg} / \mathrm{dL})] / 405$.

Salivary samples were obtained at home on another day with Salivette ${ }^{\circledR}$ tubes to assess the cortisol awakening response (calculated as the area under the curve with respect to the increase, considering three samples: awakening, 30' postawakening, and 60' post-awakening) and cortisol levels during the day (calculated as the area under the curve with respect to the ground, considering 5 samples: awakening, 30' post-awakening, 60' post-awakening, 10:00 a.m., and 11:00 p.m.). Both formulas were computed using the trapezoid formula (34). A full explanation of the processing of the samples and cortisol determination with a high-sensitivity enzyme-linked immunosorbent assay (ELISA) kit has been described elsewhere (3).

\section{Statistical Analyses}

We used SPSS v 23.0 for conducting statistical analyses. Cortisol measures were transformed with a Box-Cox transformation (35), and the Trail Making Test (part A) was log transformed (ln) to reduce skewness. Chi-squared tests and T-tests were used to compare categorical and continuous data between both diagnostic groups. Non-parametric tests (Mann Whitney U test) were used to compare ordinal variables or continuous measures that were skewed (e.g. insulin, c-peptide). Pearson correlation analyses (and Spearman when needed) were used to explore associations between continuous variables. A p value $<0.05$ (two-tailed) was considered to be significant.

As $\mathrm{HbAl}_{\mathrm{c}}$ was considered the glucose-related parameter to be studied in our main hypothesis, we verified that this value followed a normal distribution and checked for potential outliers with the 1.5 quartile (Q) rule for outliers (36). With this definition, any observation is a suspected outlier if it falls more than $1.5 \mathrm{x}$ interquartile range (IQR) above the third quartile or below the first quartile. In our sample, the distribution for $\mathrm{HbAl}_{\mathrm{c}}$ values was: minimum value= 4.6, Q1 = 4.9, Q2 (median) = 5.1, Q3 (5.3), maximum value 5.8, $\mathrm{IQR}=0.4$. Therefore, none of the values were considered outliers because they were within the limits $1.5 \mathrm{xIQR}$ (lower interval: 4.3, upper interval: 5.9).

Although our main hypothesis was conducted with multiple linear regression analyses, we first conducted an exploratory and univariate analysis to test the associations between different glucose-related parameters and cognitive outcomes. We also included exploratory correlational analyses between cognitive scores. These exploratory analyses were not adjusted for multiple comparisons following some recommendations that indicate that is it not strictly necessary to correct for multiple testing in analyses that are exploratory in nature (37). Multiple linear regression analyses were conducted for testing the association between $\mathrm{HbAl}_{\mathrm{c}}$ and cognitive variable while adjusting for covariates. Several multiple linear regression analyses were conducted, considering each cognitive task as the dependent variable. $H b A 1_{c}$ was considered the main independent variable. We avoided the inclusion of different glucose metabolism parameters in the same equation because they were highly 
correlated. The following covariates were included in each equation with the enter procedure: age, sex, education level, diagnosis, antipsychotic and benzodiazepine treatment, BMI, smoking, and HPA axis measures. Potential interactions between diagnosis and $\mathrm{HbAl}_{\mathrm{c}}$ were tested, and those significant interactions were included in the final model.

\section{Sample Size and Power Analysis}

$\mathrm{G}^{*}$ Power 3.1.9.4. was used for sample size and power calculations. The original sample was calculated for detecting a moderate effect size $\left(f^{2}=0.2\right)$ with multiple linear regression analyses, considering an alpha error of 0.05 and a beta error of 0.15 (statistical power of $85 \%$ ), and 12 predictors. The needed sample size was 108 . It is important to note that our sample is small for detecting small effects. Moreover, in the stratified analysis by diagnosis (e.g. correlation analyses), the statistical power can decrease: the statistical power for detecting moderate effect sizes $(r=0.3)$ was $59 \%$ for healthy individuals and $67 \%$ for ROP patients.

\section{RESULTS}

Clinical and hormonal variables from the sample are described in Table 1. Both groups were well matched in age and sex, although ROP patients had a lower education status and reported more smoking and alcohol consumption. In relation to glucose-related parameters, C-peptide concentrations were higher in ROP patients than in HS. There were no significant differences in HPA axis measures between groups.

ROP patients had a lower performance in all cognitive tasks than HS (Table 2). The correlation matrix between cognitive measures in all participants is described in Table 3.

Of all glucose metabolism parameters, $\mathrm{HbAl}_{\mathrm{c}}$ levels were more clearly associated with cognitive impairment in cognitive tasks dealing with executive functions and visual memory in both ROP patients and HS (Table 4).

A multivariate analysis conducted in all participants (ROP patients and $\mathrm{HS}$ ) found a significant negative association between $\mathrm{HbA} 1_{c}$ and cognitive functioning in five cognitive

TABLE 1 | Clinical characteristics and hormonal measures from the sample.

\begin{tabular}{|c|c|c|c|c|c|}
\hline \multirow[b]{2}{*}{ Female sex, N (\%) } & \multicolumn{2}{|c|}{$\begin{array}{c}\text { HS } \\
N=50\end{array}$} & \multicolumn{2}{|c|}{$\begin{array}{l}\text { ROP patients } \\
\qquad \begin{array}{c}\mathrm{N}=60 \\
\end{array}\end{array}$} & \multirow{2}{*}{$\frac{\text { p value }}{0.335}$} \\
\hline & 22 & $44 \%$ & 21 & $35 \%$ & \\
\hline Age (years) & 23.8 & 4.8 & 24.5 & 5.4 & 0.465 \\
\hline Education level (years of study) & 13.4 & 2.7 & 11.3 & 2.8 & $<0.001$ \\
\hline Smoking, N (\%) & 10 & $20 \%$ & 41 & $68.3 \%$ & $<0.001$ \\
\hline Smoking (cig/day), all participants & 1.6 & 4.4 & 9.0 & 9.6 & $<0.001$ \\
\hline Smoking (cig/day), only smokers & 8.0 & 7.0 & 13.1 & 9.0 & 0.101 \\
\hline \multicolumn{6}{|l|}{ Cannabis use, N (\%) } \\
\hline No & 38 & $76 \%$ & 43 & $71.7 \%$ & 0.215 \\
\hline Sporadic & 10 & $20 \%$ & 9 & $15 \%$ & \\
\hline Continuous & 2 & $4 \%$ & 8 & $13.3 \%$ & \\
\hline \multicolumn{6}{|l|}{ Alcohol consumption, N (\%) } \\
\hline No & 5 & $10 \%$ & 27 & $45 \%$ & $<0.001$ \\
\hline Sporadic & 44 & $88 \%$ & 28 & $46.7 \%$ & \\
\hline Continuous & 1 & $2 \%$ & 5 & $8.3 \%$ & \\
\hline $\mathrm{BMl}\left(\mathrm{kg} / \mathrm{m}^{2}\right)$ & 22.5 & 3.2 & 24.1 & 4.1 & 0.053 \\
\hline Antipsychotic treatment: & 0.0 & 0.0 & 371.1 & 334.0 & $<0.001$ \\
\hline \multicolumn{6}{|l|}{ Chlorpromazine equivalents (mg/day) } \\
\hline Benzodiazepine treatment: & 0.0 & 0.0 & 2.6 & 7.7 & 0.021 \\
\hline \multicolumn{6}{|l|}{ Diazepam equivalents (mg/day) } \\
\hline \multicolumn{6}{|l|}{ Glucose metabolism parameters } \\
\hline Glucose (mg/dL) & 78.6 & 11.2 & 78.7 & 11.1 & 0.956 \\
\hline Insulin $(\mu \mathrm{U} / \mathrm{mL})$ & 6.6 & 0 to 22.9 & 9.5 & 0 to 114 & 0.595 \\
\hline C-peptide ( $\mu \mathrm{g} / \mathrm{L})$ & 1.3 & 0.6 to 4.2 & 1.6 & 0.7 to 12.7 & 0.003 \\
\hline $\mathrm{HbA1}_{\mathrm{c}}(\%)$ & 5.1 & 0.3 & 5.1 & 0.3 & 0.250 \\
\hline HOMA-IR & 1.4 & 0 to 4.9 & 1.3 & 0 to 26.18 & 0.802 \\
\hline \multicolumn{6}{|l|}{ HPA axis measures } \\
\hline Cortisol at awakening (nmol/L) & 14.7 & 9.0 & 13.0 & 8.6 & 0.381 \\
\hline Cortisol 30' post-awakening (nmol/L) & 23.8 & 13.4 & 20.3 & 10.7 & 0.342 \\
\hline Cortisol 60' post-awakening (nmol/L) & 21.0 & 12.8 & 16.3 & 7.5 & 0.234 \\
\hline 10:00 a.m. & 12.5 & 7.4 & 12.0 & 6.4 & 0.971 \\
\hline 11:00 p.m. & 2.7 & 2.1 & 3.0 & 3.0 & 0.971 \\
\hline $\mathrm{CAR}\left(\mathrm{A \cup C} \mathrm{C}_{\mathrm{i}}\right)$ & 39.7 & 63.6 & 40.5 & 53.7 & 0.942 \\
\hline Cortisol during the day $\left(\mathrm{AUC}_{\mathrm{g}}\right)$ & 2049.6 & 837.3 & 2082.3 & 733.4 & 0.834 \\
\hline
\end{tabular}

Data are mean (SD), median (range) or $N(\%)$.

Cortisol raw data are shown. However, $p$ values were obtained using transformed cortisol values (Box-Cox transformation).

BMI, Body mass index; HbA1 ${ }_{c}$, Glycated haemoglobin; HOMA-IR, Homeostatic Model Assessment for Insulin Resistance; HPA, Hypothalamic-pituitary-adrenal; CAR, Cortisol awakening response; $A \cup C_{i}$, Area under the curve (calculated with respect to the increase); $A \cup C_{g}$, Area under the curve (calculated with respect to the ground).

Significant associations $(p<0.05)$ are represented in bold. 
TABLE 2 | Cognitive functioning by diagnostic group.

\begin{tabular}{|c|c|c|c|c|c|}
\hline & \multicolumn{2}{|c|}{$\begin{array}{c}\mathrm{HS} \\
\mathrm{N}=50\end{array}$} & \multicolumn{2}{|c|}{$\begin{array}{l}\text { ROP patients } \\
\qquad \begin{array}{l}\mathrm{N}=60\end{array}\end{array}$} & \multirow[t]{2}{*}{$p$ value } \\
\hline & Mean & SD & Mean & SD & \\
\hline \multicolumn{6}{|l|}{ Verbal learning and memory } \\
\hline HVLT-R & 27.5 & 3.8 & 22.8 & 4.9 & $<0.001$ \\
\hline \multicolumn{6}{|l|}{ Visual learning and memory } \\
\hline BVMT-R & 27.0 & 5.9 & 19.6 & 7.2 & $<0.001$ \\
\hline \multicolumn{6}{|l|}{ Working memory } \\
\hline WMS-III-SS (nonverbal) & 16.2 & 2.9 & 14.2 & 3.7 & 0.002 \\
\hline LNS (verbal) & 14.2 & 2.9 & 12.0 & 2.3 & $<0.001$ \\
\hline \multicolumn{6}{|l|}{ Processing speed } \\
\hline $\mathrm{TMT}^{+} \mathrm{A}^{\dagger}$ (seconds) & 24.7 & 8.5 & 38.2 & 13.4 & $<0.001$ \\
\hline BACS SC & 61.9 & 9.6 & 45.9 & 12.3 & $<0.001$ \\
\hline Category Fluency & 24.1 & 5.1 & 18.3 & 5.2 & $<0.001$ \\
\hline \multicolumn{6}{|c|}{ Reasoning and problem solving } \\
\hline NAB Mazes & 27.0 & 5.9 & 19.6 & 7.2 & $<0.001$ \\
\hline \multicolumn{6}{|l|}{ Attention/vigilance } \\
\hline CPT-IP & 2.7 & 0.6 & 2.0 & 0.7 & $<0.001$ \\
\hline \multicolumn{6}{|l|}{ Social cognition } \\
\hline MSCEIT-ME & 94.4 & 9.2 & 86.8 & 9.8 & $<0.001$ \\
\hline
\end{tabular}

${ }^{+}$As this cognitive test is measured in seconds, higher scores reflect poorer cognitive performance.

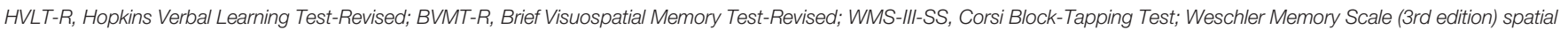

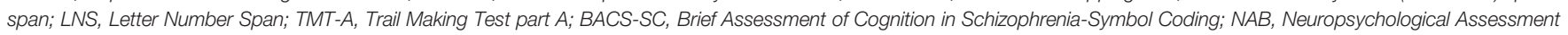
Battery; CPT-IP, Continuous Performance Test - Identical Pairs; MSCEIT-ME, Mayer-Salovey-Caruso Emotional Intelligence Test - Managing emotions.

Significant associations ( $p<0.05)$ are represented in bold.

tasks dealing with executive functions, visual memory and attention/vigilance (Table 5). A diagnosis by $\mathrm{HbA} 1_{\mathrm{c}}$ interaction was found in this latter cognitive domain, which means that the pattern in the relationship between $\mathrm{HbAl}_{\mathrm{c}}$ and attention/vigilance differs between ROP patients and HS: in ROP patients, higher $\mathrm{HbAl}_{\mathrm{c}}$ levels are associated with impaired attention and vigilance, but this pattern does not apply to HS. This interaction is also described in Figure 1. As it is observed in this figure, the interaction is driven by higher $H b A 1_{c}$ values. Although there were no outliers in our sample, we repeated a sensitivity analysis excluding the two higher values $\left(\mathrm{HbAl}_{\mathrm{c}}=\right.$ $5.8 \%)$ to explore whether the interaction was influenced for these

TABLE 3 | Pearson's correlations studying the relationship between cognitive tasks in 110 participants.

\begin{tabular}{|c|c|c|c|c|c|c|c|c|c|c|c|}
\hline & & HVLT-R & BVMT-R & WMS-III SS & LNS & TMT-A $^{\dagger}$ & BACS SC & Fluency & NAB Mazes & CPT-IP & MSCEIT-ME \\
\hline HVLT-R & $p$ value & & $<0.001$ & $<0.001$ & $<0.001$ & $<0.001$ & $<0.001$ & $<0.001$ & .007 & $<0.001$ & $<0.001$ \\
\hline & $p$ value & $<0.001$ & & $<0.001$ & $<0.001$ & $<0.001$ & $<0.001$ & $<0.001$ & $<0.001$ & $<0.001$ & 0.086 \\
\hline \multirow[t]{2}{*}{ WMS-III SS } & r & 0.469 & 0.599 & 1 & 0.387 & -0.546 & 0.504 & 0.417 & 0.553 & 0.376 & 0.300 \\
\hline & $p$ value & $<0.001$ & $<0.001$ & & $<0.001$ & $<0.001$ & $<0.001$ & $<0.001$ & $<0.001$ & $<0.001$ & 0.002 \\
\hline LNS & $r$ & 0.539 & 0.554 & 0.387 & 1 & -0.536 & 0.605 & 0.473 & 0.367 & 0.610 & 0.286 \\
\hline TMT-A $^{\dagger}$ & $p$ value & $<0.001$ & $<0.001$ & $<0.001$ & $<0.001$ & & $<0.001$ & $<0.001$ & $<0.001$ & $<0.001$ & .001 \\
\hline \multirow[t]{2}{*}{ BACS SC } & r & 0.675 & 0.690 & 0.504 & 0.605 & -0.707 & 1 & 0.653 & 0.494 & 0.635 & 0.312 \\
\hline & $p$ value & $<0.001$ & $<0.001$ & $<0.001$ & $<0.001$ & $<0.001$ & & $<0.001$ & $<0.001$ & $<0.001$ & 0.001 \\
\hline \multirow[t]{2}{*}{ Fluency } & $r$ & 0.594 & 0.624 & 0.417 & 0.473 & -0.559 & 0.653 & 1 & 0.495 & 0.519 & 0.220 \\
\hline & $p$ value & $<0.001$ & $<0.001$ & $<0.001$ & $<0.001$ & $<0.001$ & $<0.001$ & & $<0.001$ & $<0.001$ & 0.024 \\
\hline NAB Mazes & $r$ & 0.256 & 0.549 & 0.553 & 0.367 & -0.545 & 0.494 & 0.495 & 1 & 0.447 & 0.173 \\
\hline MSCEIT-ME & $p$ value & $<0.001$ & 0.086 & 0.002 & 0.004 & 0.001 & 0.001 & 0.024 & 0.078 & 0.002 & \\
\hline
\end{tabular}

${ }^{\dagger}$ As TMT-A is measured in seconds, greater scores in this variable reflect poorer cognitive performance. For this reason, this variable showed negative correlations with other cognitive tasks. The log transformed variable (In TMT-A) was used.

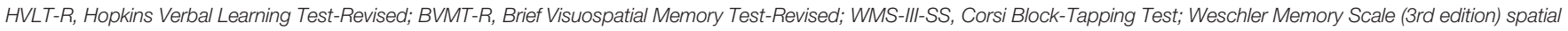

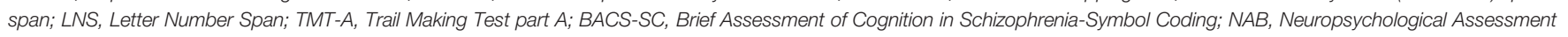
Battery; CPT-IP, Continuous Performance Test - Identical Pairs; MSCEIT-ME, Mayer-Salovey-Caruso Emotional Intelligence Test - Managing emotions. 
TABLE 4 | Correlations between glucose-related parameters and cognitive tasks: Stratified analyses by diagnosis.

\begin{tabular}{|c|c|c|c|c|c|c|c|c|c|c|c|}
\hline & & \multicolumn{5}{|c|}{ HS } & \multicolumn{5}{|c|}{ ROP patients } \\
\hline & & HbA1c & Glucose & C-peptide & Insulin & HOMA-IR & HbA1c & Glucose & C-peptide & Insulin & HOMA-IR \\
\hline \multirow[t]{2}{*}{ HVLT-R } & $r$ & 0.012 & -0.080 & -0.014 & -0.152 & -0.160 & -0.076 & 0.120 & 0.023 & 0.076 & 0.063 \\
\hline & $p$ value & 0.935 & 0.582 & 0.921 & 0.292 & 0.271 & 0.567 & 0.366 & 0.863 & 0.567 & 0.634 \\
\hline \multirow[t]{2}{*}{ BVMT-R } & $r$ & -0.350 & -0.238 & 0.000 & -0.169 & -0.184 & -0.262 & -0.002 & -0.031 & 0.033 & 0.028 \\
\hline & $p$ value & 0.013 & 0.096 & 0.999 & 0.242 & 0.205 & 0.047 & 0.985 & 0.817 & 0.806 & 0.835 \\
\hline \multirow[t]{2}{*}{ WMS-III SS } & $r$ & -0.295 & -0.285 & -0.155 & -0.395 & -0.370 & -0.218 & 0.052 & -0.343 & -0.102 & -0.072 \\
\hline & $p$ value & 0.037 & 0.045 & 0.283 & 0.005 & 0.009 & 0.097 & 0.695 & 0.008 & 0.442 & 0.590 \\
\hline \multirow[t]{2}{*}{ LNS } & r & -0.157 & -0.092 & 0.055 & -0.231 & -0.258 & -0.348 & -0.134 & -0.128 & -0.104 & -0.102 \\
\hline & $p$ value & 0.276 & 0.524 & 0.707 & 0.106 & 0.073 & 0.010 & 0.332 & 0.357 & 0.454 & 0.461 \\
\hline \multirow[t]{2}{*}{ TMT-A } & $r$ & 0.135 & 0.047 & -0.050 & 0.091 & 0.081 & 0.330 & -0.046 & 0.199 & 0.016 & -0.008 \\
\hline & $p$ value & 0.349 & 0.747 & 0.732 & 0.528 & 0.579 & 0.011 & 0.729 & 0.131 & 0.901 & 0.955 \\
\hline \multirow[t]{2}{*}{ BACS SC } & r & -0.329 & -0.250 & -0.152 & -0.351 & -0.375 & -0.176 & 0.048 & -0.002 & 0.055 & 0.050 \\
\hline & $p$ value & 0.020 & 0.080 & 0.292 & 0.013 & 0.008 & 0.182 & 0.721 & 0.986 & 0.677 & 0.706 \\
\hline \multirow[t]{2}{*}{ Fluency } & $r$ & -0.002 & -0.070 & 0.076 & -0.215 & -0.202 & -0.106 & 0.214 & -0.044 & 0.061 & 0.073 \\
\hline & $p$ value & 0.987 & 0.629 & 0.598 & 0.134 & 0.165 & 0.426 & 0.107 & 0.745 & 0.648 & 0.585 \\
\hline \multirow[t]{2}{*}{ NAB Mazes } & r & -0.243 & -0.093 & 0.151 & 0.020 & 0.010 & -0.425 & -0.067 & -0.174 & 0.021 & 0.050 \\
\hline & $\mathrm{p}$ value & 0.089 & 0.520 & 0.295 & 0.890 & 0.944 & 0.001 & 0.620 & 0.191 & 0.877 & 0.712 \\
\hline \multirow[t]{2}{*}{ CPT-IP } & r & -0.037 & -0.042 & -0.123 & -0.248 & -0.265 & -0.262 & 0.049 & -0.015 & 0.138 & 0.145 \\
\hline & $p$ value & 0.800 & 0.775 & 0.397 & 0.082 & 0.066 & 0.047 & 0.717 & 0.912 & 0.303 & 0.277 \\
\hline \multirow[t]{2}{*}{ MSCEIT-ME } & r & -0.252 & -0.268 & -0.038 & -0.295 & -0.323 & -0.137 & 0.036 & -0.155 & 0.024 & 0.018 \\
\hline & $p$ value & 0.078 & 0.060 & 0.793 & 0.037 & 0.024 & 0.318 & 0.797 & 0.259 & 0.863 & 0.897 \\
\hline
\end{tabular}

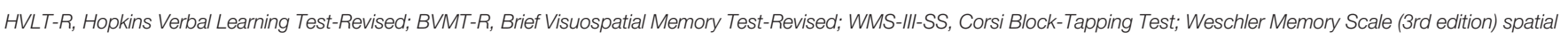

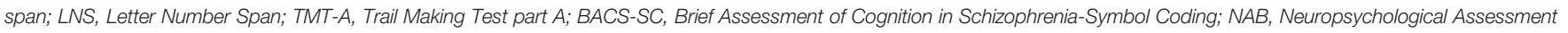
Battery; CPT-IP, Continuous Performance Test - Identical Pairs; MSCEIT-ME, Mayer-Salovey-Caruso Emotional Intelligence Test - Managing emotions.

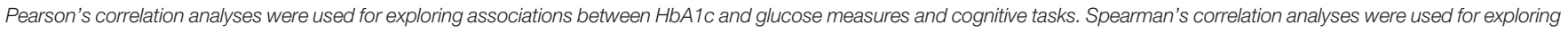
associations between c-peptide, insulin and HOMA-IR, and cognitive tasks.

values, and this was the case because the interaction term lost its significance when these two higher values were excluded from the analyses.

\section{DISCUSSION}

In our study that explored whether glucose metabolism parameters may contribute to the explanation, at least in part, of the cognitive deficits of individuals diagnosed with a ROP, we found that $\mathrm{HbAl}_{\mathrm{c}}$ contributed to a poorer cognitive performance in domains related to processing speed, executive functions and visual memory in both the ROP patients and the HS, whereas it was associated with poorer attention and vigilance only in the ROP group.

With the main aim of a better understanding of the molecular, cellular, and other system disturbances in patients with schizophrenia, biomarkers of diagnosis, prognosis, or treatment response have been recommended (38). The study of glucose metabolism parameters in this population is of special interest since patients with schizophrenia have a three-fold risk of

TABLE 5 | Multiple linear regression analyses exploring the relationship between $\mathrm{HbA1} 1_{\mathrm{C}}$ and cognitive abilities.

Unadjusted model

\begin{tabular}{ccccccc}
\hline $\mathbf{R}^{\mathbf{2}}$ & $\boldsymbol{\beta}$ & $\mathbf{p}$ value & $\mathbf{R}^{\mathbf{2}}$ & $\boldsymbol{\beta}$ & $\mathbf{p}$ value & Significant interactions \\
0.0002 & 0.016 & 0.871 & 0.465 & -0.014 & 0.862 & None \\
0.038 & -0.194 & $\mathbf{0 . 0 4 3}$ & 0.486 & -0.189 & $\mathbf{0 . 0 1 7}$ & None \\
0.041 & -0.202 & $\mathbf{0 . 0 3 4}$ & 0.371 & -0.143 & 0.100 & None \\
0.029 & -0.169 & 0.077 & 0.292 & -0.170 & 0.065 & None \\
0.02 & 0.143 & 0.137 & 0.474 & 0.160 & $\mathbf{0 . 0 4 4}$ & None \\
0.015 & -0.124 & 0.197 & 0.617 & -0.136 & $\mathbf{0 . 0 4 4}$ & None \\
0.0001 & 0.010 & 0.914 & 0.417 & -0.014 & 0.864 & None \\
0.082 & -0.287 & $\mathbf{0 . 0 0 2}$ & 0.407 & -0.290 & $\mathbf{0 . 0 0 1}$ & None \\
0.008 & -0.089 & 0.355 & 0.489 & 0.021 & 0.816 & ROP $\times \mathrm{HbA} 1_{c}: \beta=-1.888 ; p=\mathbf{0 . 0 1 6}$ \\
0.015 & -0.121 & 0.208 & 0.337 & -0.099 & 0.266 & None
\end{tabular}

$\beta$, Standardized beta regression coefficient (for HbA1c); HVLT-R, Hopkins Verbal Learning Test-Revised; BVMT-R, Brief Visuospatial Memory Test-Revised; WMS-III-SS, Corsi BlockTapping Test; Weschler Memory Scale (3rd edition) spatial span; LNS, Letter Number Span; TMT-A, Trail Making Test part A; BACS-SC, Brief Assessment of Cognition in SchizophreniaSymbol Coding; NAB, Neuropsychological Assessment Battery; CPT-IP, Continuous Performance Test - Identical Pairs; MSCEIT-ME, Mayer-Salovey-Caruso Emotional Intelligence Test - Managing emotions.

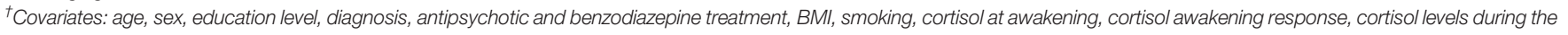
day $\left(A \cup C_{g}\right)$.

Significant associations $(p<0.05)$ are represented in bold. 


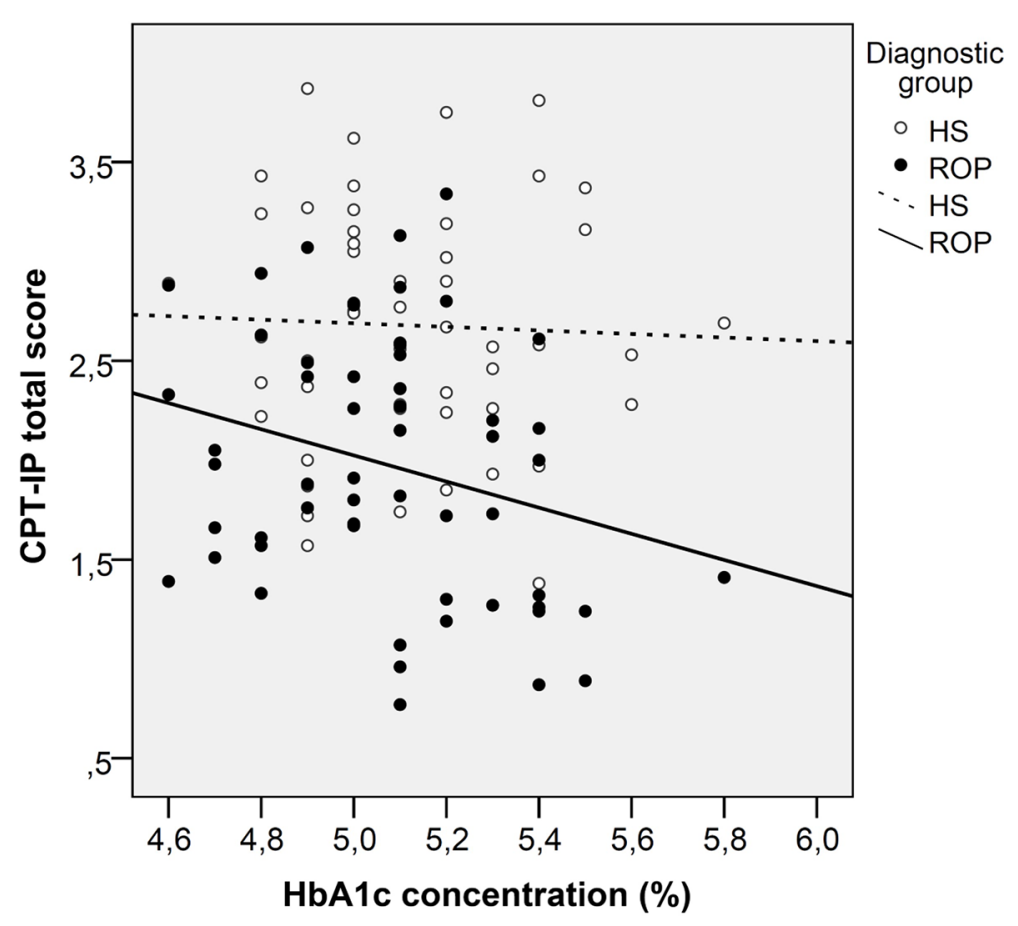

FIGURE 1 | Scatterplot graph of the association between glycated haemoglobin and attention in patients with a recent-onset psychosis and healthy subjects. ROP, Recent-onset psychosis; HS, Healthy subjects.

diabetes compared to the general population (39), and it gives us the opportunity to investigate pathogenic processes underlying both disturbances, with the aim of discovering new treatment strategies.

Biomarkers of schizophrenia have been widely used in recent years. They are frequently divided into two groups: peripheral and central biomarkers. The central nervous system and the periphery are strongly connected, a fact that has revealed the relevance of blood-based parameters as biomarkers in schizophrenia. Once again, several classifications for biomarkers have examined molecules modulating brain functions. Biomarkers have then been divided into inflammatory biomarkers, neuroendocrine biomarkers, neurotransmitters (well-documented and deeply understood), and metabolic biomarkers (38). The last may include indicators of metabolic syndrome or insulin resistance (13) that have been proven to discriminate between patients with or without metabolic syndrome. Furthermore, for many years, increased glucose concentrations, insulin resistance, and impaired glucose tolerance $(13,40)$ have been reported to be present in drug-naïve first-episode psychosis patients compared to HS. However, in our study, we did not find significant differences in most glucose-related parameters, except for C-peptide between ROP patients and HS.

In our study, in terms of all glucose parameters, $\mathrm{HbA} 1_{c}$ levels were found to be associated with poorer cognitive performance, particularly in those cognitive tasks assessing executive function and visual memory in both groups, ROP patients and HS. These findings agree with a recent study carried out by Zhang et al. (24), who found this parameter to be correlated with poorer global cognition and attention in men suffering from schizophrenia.
Other studies (23) have reported an association between glucose intolerance and more severe negative symptoms and poorer social cognition, although no associations were found for neurocognitive performance. There is also a meta-analysis suggesting that type 2 diabetes is associated with more severe cognitive deficits in schizophrenia (16). Interestingly, in a metaanalysis (21) exploring different glucose-related biomarkers and cognitive impairment in people with type 2 diabetes, high $\mathrm{HbAl}_{\mathrm{c}}$ was negatively associated with cognitive function. Our study is in accordance with this last study, as we found a greater association for $H b A 1_{c}$ than for other fasting-related glucose parameters. These results are seemingly in agreement with a recent study investigating glucose metabolic parameters associated with cognition and white matter microstructure in healthy young populations (22). $\mathrm{HbA} 1_{\mathrm{c}}$ levels (even under the diagnostic values for diabetes mellitus) were inversely correlated with measures of cognitive performance. Moreover, this low-grade $\mathrm{HbAl}_{\mathrm{c}}$ variation negatively affected white matter integrity, that also correlated with cognitive function. This study supports our findings related to the transdiagnostic relationship between $\mathrm{HbA} 1_{c}$ and cognitive function, as associations between these measures were observed in both ROP patients and healthy controls.

In contrast with other cognitive domains, attention was negatively associated with $\mathrm{HbAl}_{\mathrm{c}}$ in ROP patients but not in HS. It is not clear why a distinct pattern could exist between ROP patients and HS in this particular domain. Previous studies that have measured allostatic load, an index that reflects systemic biological dysregulations including glucose homeostasis 
parameters (glucose and insulin), have reported associations with poorer attention in ROP patients but not in HS (41). In another double-blind, placebo-controlled experimental study that assessed the effects of multiple-dose oral glucose administration on cognition in younger and older patients with schizophrenia and HS, a decrease in attentional performance at the $75 \mathrm{~g}$ glucose dose, when compared to placebo, was found in younger patients with schizophrenia (42). These findings suggest that glucose metabolism parameters might differentially affect ROP patients and HS in the attention and vigilance domains. However, it is also important to mention that this interaction was driven by higher $\mathrm{HbAl}_{\mathrm{c}}$ values, as the interaction lost its significance when analyses were restricted to people with $\mathrm{HbAl}_{\mathrm{c}}$ below $5.8 \%$. The $\mathrm{HbAl}_{\mathrm{c}}$ range of our sample was also low, which limits the possibility of finding associations between cognitive outcomes and this glucose-related biomarker. Further studies might improve this issue by including a sample with a greater proportion of patients with glucose intolerance. This can be achieved by recruiting patients with a longer duration of the illness, because pre-diabetes and diabetes might increase over time. As only $16 \%$ of patients with first episode psychosis show abnormal glucose tolerance (13), the recruitment of patients with psychotic disorders at early stages of the illness might explain the narrow range of $\mathrm{HbAl}_{\mathrm{c}}$ levels in our sample.

The negative correlation between $\mathrm{HbAl}_{\mathrm{c}}$ and cognitive performance found in our study may be partially explained by the fact that cognitive tasks associated with $\mathrm{HbAl}_{\mathrm{c}}$ are mainly those implicating hippocampal functions and the prefrontal cortex, a hypothesis that is supported by a recent review (43). Continuous exposure to glucose and prediabetes have been significantly associated with structural brain abnormalities such as decreased brain volume and grey matter and white matter volume (44). Further, the risk of brain infarcts and decreased hippocampal volume may be associated with continuous exposure to glucose, which is reflected by higher levels of $\mathrm{HbAl}_{\mathrm{c}}$. This indicator of longterm glycaemic control is also thought to impact negatively on white matter structure even in healthy individuals (22). This last study suggests that biological processes other than microvascular and macrovascular disease could be playing a role in this associations. As pointed out by Repple et al. (22), it is plausible that inflammatory processes might constitute one of several biological mechanisms potentially mediating the relationship between glycose dysregulation and brain structural damage. This is a particularly important issue to be studied because the low-grade inflammation is also found in people with psychotic disorders (45-47), even before the onset of the disease $(48,49)$, and is associated with poorer cognitive function $(9,50)$. The duration of postpandrial glucose increase, a major contributor to chronic hyperglycaemia (and higher $H b 1_{c}$ ), is also thought to contribute to excessive protein glycation, generation of oxidative stress and inflammation (51). Future longitudinal studies are needed to explore whether the association between $\mathrm{HbAl}_{\mathrm{c}}$ levels and impaired cognitive function could be explained by changes in inflammatory markers.

Recently, some authors have hypothesized that central insulin resistance could have an important role in the relationship between metabolic and cognitive disorders (52). There is consistent evidence pointing out that the dopamine system has an important role in glucose homeostasis control because the dopaminergic and insulin signalling pathways influence each other (53-55) and that both central nervous system insulin and striatal dopamine can regulate peripheral glucose homeostasis (56). Given the central importance of dopaminergic dysregulation, cognitive deficits, and metabolic dysfunction in schizophrenia (57-59), the potential role of central nervous system insulin signalling in the pathophysiology of schizophrenia is an interesting field to be explored. This knowledge could help in the exploration and development of future therapeutic strategies.

For most cognitive domains, with the exception of attention and vigilance, the association between $\mathrm{HbAl}_{\mathcal{c}}$, and cognition was not specific for patients with ROP. Moreover, ROP patients and HS had similar $\mathrm{HbAl}_{\mathrm{c}}$ levels, which were in the normal range. These findings suggest that subtle differences in $\mathrm{HbAl}_{\mathrm{c}}$ could have a significant impact on cognitive processing independent of diagnosis. As our study has a cross-sectional design and includes psychotic patients who are at early stages of the disease, our study does not allow us to infer causality. Future longitudinal studies are needed to explore whether longitudinal changes in glucose metabolic parameters (mainly $\mathrm{HbAl}_{\mathrm{c}}$ ) could contribute to cognitive impairment in patients with schizophrenia. This is an important hypothesis to be tested, as chronic antipsychotic treatment is associated with weight gain and metabolic abnormalities, including the risk of type 2 diabetes (60). If our results are replicated in longitudinal studies, therapeutic agents that improve insulin sensitivity and promote neurogenesis, such as metformin (61), could be considered cognitive enhancement options for people with ROP and higher $\mathrm{HbA} 1_{c}$ values.

The results regarding $\mathrm{HbAl}_{\mathrm{c}}$ and cognitive performance were independent of HPA axis activity, as all multivariate analyses were adjusted for cortisol levels during the day and the CAR. These two HPA axis measures have been reported to be associated with impaired cognitive functioning in ROP patients (4): a blunted CAR has been associated with poorer verbal memory in ROP patients (27), higher afternoon plasma cortisol levels are associated with poorer verbal memory (62), and a more flattened diurnal cortisol slope has been associated with poorer working memory in women with ROP (3). It is also important to control for HPA axis activity when exploring the role of glucose-related parameters on cognition because a central dysregulation of the HPA axis has been reported in type 2 diabetes and because higher morning cortisol levels are associated with poorer cognitive abilities in people with type 2 diabetes (28). In patients with type 2 diabetes, there are elevated basal plasma cortisol and ACTH levels (63-65), higher late-night cortisol (66), and increased cortisol levels following overnight dexamethasone suppression $(67,68)$.

Several strengths of our study should be noted. The patients in our study seemed to be representative of our catchment area, and our first-episode psychosis unit is a referral center in our area. On the other hand, to the best of our knowledge, few studies have tried to specifically investigate metabolic biomarkers for cognition in schizophrenia. Although some studies have 
explored the association between diabetes mellitus and poorer cognitive functioning in patients with schizophrenia $(16,24)$, our study is the first to specifically highlight the relationship between $\mathrm{HbA} 1_{c}$ and cognitive function in the early stages of the psychotic illness. The search for biomarkers in cognition has been the focus of interest in research on patients with schizophrenia (50). However, in recent decades, the vast majority of studies have investigated whether neurotrophic factors or inflammatory markers may be correlated with cognitive deficits or cognitive recovery in schizophrenia (50), and metabolic parameters have been a second focus of interest.

The main limitation of our study is the cross-sectional design. Therefore, no causal relationships between glucose metabolism parameters and cognitive functioning can be inferred. The relatively small sample size limits the possibility of the conduction of specific subanalyses regarding sex differences or psychotic phenotypes. Larger studies are needed to test whether the role of $H b A 1_{c}$ on cognitive outcomes differs by subtypes of psychotic disorders. The CAR was obtained only on one day, as consensus guidelines (69) recommend obtaining repeated measures for this parameter on separate days. As in the original study (3), we administered dexamethasone to all participants, and we decided to measure the CAR only on one day. Finally, a replication dataset was not included.

In summary, the present study suggests that long-term exposure to higher glucose levels, although within the normal range, is negatively associated with cognitive performance in both ROP patients and HS in tasks dealing with executive functions and visual memory, two cognitive domains that involve the hippocampus and prefrontal cortex. Our study suggests that this association is independent of BMI and HPA axis functioning. These findings highlight the importance of the consideration of the inclusion of $\mathrm{HbAl}_{\mathrm{c}}$ in future longitudinal studies exploring cognitive changes in patients with a psychotic disorder at early stages of the disease to disentangle a potential negative effect on cognitive outcomes.

\section{REFERENCES}

1. Fett AKJ, Viechtbauer W, Dominguez M de G, Penn DL, van Os J, Krabbendam L. The relationship between neurocognition and social cognition with functional outcomes in schizophrenia: A meta-analysis. Neurosci Biobehav Rev (2011) 35:573-88. doi: 10.1016/j.neubiorev. 2010.07.001

2. Fusar-Poli P, Deste G, Smieskova R, Barlati S, Yung AR, Howes O, et al. Cognitive functioning in prodromal psychosis: a meta-analysis. Arch Gen Psychiatry (2012) 69:562-71. doi: 10.1001/archgenpsychiatry.2011.1592

3. Labad J, Gutiérrez-Zotes A, Creus M, Montalvo I, Cabezas Á, Solé M, et al. Hypothalamic-pituitary-adrenal axis measures and cognitive abilities in early psychosis: Are there sex differences? Psychoneuroendocrinology (2016) 72:5462. doi: 10.1016/j.psyneuen.2016.06.006

4. Labad J. The role of cortisol and prolactin in the pathogenesis and clinical expression of psychotic disorders. Psychoneuroendocrinology (2019) 102:2436. doi: 10.1016/j.psyneuen.2018.11.028

5. Barbero JD, Gutiérrez-Zotes A, Montalvo I, Creus M, Cabezas Á, Solé M, et al. Free thyroxine levels are associated with cognitive abilities in subjects with

\section{DATA AVAILABILITY STATEMENT}

The datasets generated for this study will not be made publicly available. The datasets are not publicly available due to privacy or ethical restrictions. However, additional analyses might be available from authors by request to the corresponding author.

\section{ETHICS STATEMENT}

The studies involving human participants were reviewed and approved by Hospital Sant Joan Ethics Committee. The patients/ participants provided their written informed consent to participate in this study.

\section{AUTHOR CONTRIBUTIONS}

JL, AG-Z, and EV designed the study. IM, ÁC, MS, VS-G, MA, and LO participated in the recruitment of participants. LM and EV participated in the biochemical determinations. JL and IM analyzed the data. IM and AG-R reviewed the scientific literature and wrote the first draft of the manuscript. All authors participated in the discussion of the results and approved the final manuscript.

\section{FUNDING}

This work was funded in part by the Instituto de Salud Carlos III (PI10/01607; PI15/01386) and by La Fundació de la Marató de TV3 (92230). JL and IM have received an Intensification of the Research Activity Grant by the Health Department from the Generalitat de Catalunya (SLT006/17/00012 and SLT008/18/00074). JL has also received an Intensification of the Research Activity Grant by the Instituto de Salud Carlos III in 2020 (INT19/00071). early psychosis. Schizophr Res (2015) 166:37-42. doi: 10.1016/ j.schres.2015.04.030

6. Labad J, Barbero JD, Gutiérrez-Zotes A, Montalvo I, Creus M, Cabezas Á, et al. Free thyroxine levels are associated with cognitive changes in individuals with a first episode of psychosis: A prospective 1-year follow-up study. Schizophr Res (2016) 171:182-6. doi: 10.1016/j.schres. 2016.01.036

7. Montalvo I, Nadal R, Armario A, Gutiérrez-Zotes A, Creus M, Cabezas Á, et al. Sex differences in the relationship between prolactin levels and impaired processing speed in early psychosis. Aust N Z J Psychiatry (2018) 52:585-95. doi: 10.1177/0004867417744254

8. Montalvo I, Gutiérrez-Zotes A, Creus M, Monseny R, Ortega L, Franch J, et al. Increased prolactin levels are associated with impaired processing speed in subjects with early psychosis. PloS One (2014) 9:e89428. doi: 10.1371/ journal.pone.0089428

9. Cabrera B, Bioque M, Penadés R, González-Pinto A, Parellada M, Bobes J, et al. Cognition and psychopathology in first-episode psychosis: are they related to inflammation? Psychol Med (2016) 46:2133-44. doi: 10.1017/ S0033291716000659 
10. Ribeiro-Santos A, Lucio Teixeira A, Salgado JV. Evidence for an immune role on cognition in schizophrenia: a systematic review. Curr Neuropharmacol (2014) 12:273-80. doi: 10.2174/1570159X1203140511160832

11. Fanous AH, Kendler KS. Genetics of clinical features and subtypes of schizophrenia: A review of the recent literature. Curr Psychiatry Rep (2008) 10:164-70. doi: 10.1007/s11920-008-0028-z

12. Ryan MCM, Collins $P$, Thakore JH. Impaired fasting glucose tolerance in firstepisode, drug-naive patients with schizophrenia. Am J Psychiatry (2003) 160:284-9. doi: 10.1176/appi.ajp.160.2.284

13. Fernandez-Egea E, Bernardo M, Donner T, Conget I, Parellada E, Justicia A, et al. Metabolic profile of antipsychotic-naive individuals with non-affective psychosis. Br J Psychiatry (2009) 194:434-8. doi: 10.1192/bjp.bp.108.052605

14. Fernandez-Egea E, Miller B, Bernardo M, Donner T, Kirkpatrick B. Parental history of Type 2 diabetes in patients with nonaffective psychosis. Schizophr Res (2008) 98:302-6. doi: 10.1016/j.schres.2007.10.002

15. Habtewold TD, Islam MA, Liemburg EJ, Bartels-Velthuis AAA, van Beveren NJ, Cahn W, et al. Polygenic risk score for schizophrenia was not associated with glycemic level (HbAlc) in patients with non-affective psychosis: Genetic Risk and Outcome of Psychosis (GROUP) cohort study. J Psychosom Res (2020) 132:109968. doi: 10.1016/j.jpsychores.2020.109968

16. Bora E, Akdede BB, Alptekin K. The relationship between cognitive impairment in schizophrenia and metabolic syndrome: A systematic review and meta-analysis. Psychol Med (2017) 47:1030-40. doi: 10.1017/ S0033291716003366

17. Marden JR, Mayeda ER, Tchetgen Tchetgen EJ, Kawachi I, Glymour MM. High Hemoglobin Alc and Diabetes Predict Memory Decline in the Health and Retirement Study. Alzheimer Dis Assoc Disord (2017) 31:48-54. doi: 10.1097/WAD.0000000000000182

18. Gao Y, Xiao Y, Miao R, Zhao J, Cui M, Huang G, et al. The prevalence of mild cognitive impairment with type 2 diabetes mellitus among elderly people in China: A cross-sectional study. Arch Gerontol Geriatr (2016) 62:138-42. doi: 10.1016/j.archger.2015.09.003

19. Cooper C, Sommerlad A, Lyketsos CG, Livingston G. Modifiable predictors of dementia in mild cognitive impairment: A systematic review and metaanalysis. Am J Psychiatry (2015) 172:323-34. doi: 10.1176/appi.ajp.2014. 14070878

20. Yuan XY, Wang XG. Mild cognitive impairment in type 2 diabetes mellitus and related risk factors: A review. Rev Neurosci (2017) 28:715-23. doi: 10.1515/revneuro-2017-0016

21. Geijselaers SLC, Sep SJS, Stehouwer CDA, Biessels GJ. Glucose regulation, cognition, and brain MRI in type 2 diabetes: A systematic review. Lancet Diabetes Endocrinol (2015) 3:75-89. doi: 10.1016/S2213-8587(14)70148-2

22. Repple J, Karliczek G, Meinert S, Förster K, Grotegerd D, Goltermann J, et al. Variation of HbAlc affects cognition and white matter microstructure in healthy, young adults. Mol Psychiatry (2019). doi: 10.1038/s41380-019-0504-3

23. Chen DC, Du XD, Yin GZ, Yang KB, Nie Y, Wang N, et al. Impaired glucose tolerance in first-episode drug-naïve patients with schizophrenia: Relationships with clinical phenotypes and cognitive deficits. Psychol Med (2016) 46:3219-30. doi: 10.1017/S0033291716001902

24. Zhang BH, Han M, Zhang XY, Hui L, Jiang SR, De YF, et al. Gender differences in cognitive deficits in schizophrenia with and without diabetes. Compr Psychiatry (2015) 63:1-9. doi: 10.1016/j.comppsych.2015.07.003

25. Agarwal SM, Kowalchuk C, Castellani L, Costa-Dookhan KA, Caravaggio F, Asgariroozbehani R, et al. Brain insulin action: Implications for the treatment of schizophrenia. Neuropharmacology (2019) 168:107655. doi: 10.1016/ j.neuropharm.2019.05.032

26. Cullen AE, Zunszain PA, Dickson H, Roberts RE, Fisher HL, Pariante CM, et al. Cortisol awakening response and diurnal cortisol among children at elevated risk for schizophrenia: Relationship to psychosocial stress and cognition. Psychoneuroendocrinology (2014) 46:1-13. doi: 10.1016/ j.psyneuen.2014.03.010

27. Aas M, Dazzan P, Mondelli V, Toulopoulou T, Reichenberg A, Di Forti M, et al. Abnormal cortisol awakening response predicts worse cognitive function in patients with first-episode psychosis. Psychol Med (2011) 41:463-76. doi: 10.1017/S0033291710001170

28. Reynolds RM, Strachan MWJ, Labad J, Lee AJ, Frier BM, Fowkes FG, et al. Morning cortisol levels and cognitive abilities in people with type 2 diabetes:
The Edinburgh type 2 diabetes study. Diabetes Care (2010) 33:714-20. doi: $10.2337 / \mathrm{dc} 09-1796$

29. Wing JK, Babor T, Brugha T, Burke J, Cooper JE, Giel R, et al. SCAN. Schedules for Clinical Assessment in Neuropsychiatry. Arch Gen Psychiatry (1990) 47:589-93. doi: 10.1001/archpsyc.1990.01810180089012

30. Kay SR, Fiszbein A, Vital-Herne M, Fuentes LS. The Positive and Negative Syndrome Scale-Spanish adaptation. J Nerv Ment Dis (1990) 178:510-7. doi: 10.1097/00005053-199017880-00007

31. Peralta V, Cuesta MJ. Validacion de la escala de los síndromes positivo y negativo (PANSS) en una muestra de esquizofrénicos españoles. Actas Luso Esp Neurol Psiquiatr Cienc Afines (1994) 22:171-7.

32. Nuechterlein KH, Green MF, Kern RS, Baade LE, Barch DM, Cohen JD, et al. The MATRICS Consensus Cognitive Battery, part 1: test selection, reliability, and validity. Am J Psychiatry (2008) 165:203-13. doi: 10.1176/appi.ajp.2007.07010042

33. Gardner DM, Murphy AL, O’Donnell H, Centorrino F, Baldessarini RJ. International consensus study of antipsychotic dosing. Am J Psychiatry (2010) 167:686-93. doi: 10.1176/appi.ajp.2009.09060802

34. Pruessner JC, Kirschbaum C, Meinlschmid G, Hellhammer DH. Two formulas for computation of the area under the curve represent measures of total hormone concentration versus time-dependent change. Psychoneuroendocrinology (2003) 28:916-31. doi: 10.1016/S0306-4530(02)00108-7

35. Miller R, Plessow F. Transformation techniques for cross-sectional and longitudinal endocrine data: Application to salivary cortisol concentrations. Psychoneuroendocrinology (2013) 38:941-6. doi: 10.1016/j.psyneuen.2012.09.013

36. Olsen W. Outliers. In: Data Collection: Key Debates and Methods in Social Research. London: SAGE Publications Ltd. (2012). doi: 10.4135/ 9781473914230.n32

37. Bender R, Lange S. Adjusting for multiple testing - When and how? J Clin Epidemiol (2001) 54:343-9. doi: 10.1016/S0895-4356(00)00314-0

38. Perkovic MN, Erjavec GN, Strac DS, Uzun S, Kozumplik O, Pivac N. Theranostic biomarkers for schizophrenia. Int J Mol Sci (2017) 18:pii: E733. doi: 10.3390/ijms 18040733

39. Rajkumar AP, Horsdal HT, Wimberley T, Cohen D, Mors O, Børglum AD, et al. Endogenous and antipsychotic-related risks for diabetes mellitus in young people with schizophrenia: A danish population-based cohort study. Am J Psychiatry (2017) 174:686-94. doi: 10.1176/appi.ajp.2016.16040442

40. Petrikis P, Tigas S, Tzallas AT, Papadopoulos I, Skapinakis P, Mavreas V. Parameters of glucose and lipid metabolism at the fasted state in drug-naive first-episode patients with psychosis: Evidence for insulin resistance. Psychiatry Res (2015) 229:901-4. doi: 10.1016/j.psychres.2015.07.041

41. Piotrowski P, Kotowicz K, Rymaszewska J, Beszłej JA, Plichta P, Samochowiec $\mathrm{J}$, et al. Allostatic load index and its clinical correlates at various stages of psychosis. Schizophr Res (2019) 210:73-80. doi: 10.1016/j.schres.2019.06.009

42. Fucetola R, Newcomer JW, Craft S, Melson AK. Age- and dose-dependent glucose-induced increases in memory and attention in schizophrenia. Psychiatry Res (1999) 88:1-13. doi: 10.1016/S0165-1781(99)00063-3

43. Zhou J, Zhang Z, Zhou H, Qian G. Diabetic Cognitive Dysfunction: From Bench to Clinic. Curr Med Chem (2019). doi: 10.2174/1871530319666190206225635

44. van Agtmaal MJM, Houben AJHM, de Wit V, Henry RMA, Schaper NC, Dagnelie PC, et al. Prediabetes is associated with structural brain abnormalities: The Maastricht study. Diabetes Care (2018) 41:2535-43. doi: $10.2337 / \mathrm{dc} 18-1132$

45. Kirkpatrick B, Miller BJ. Inflammation and schizophrenia. Schizophr Bull (2013) 39:1174-9. doi: 10.1093/schbul/sbt141

46. Soria V, Uribe J, Salvat-Pujol N, Palao D, Menchón JM, Labad J. Psychoneuroimmunology of mental disorders. Rev Psiquiatr Salud Ment (2018) 11:115-24. doi: 10.1016/j.rpsm.2017.07.006

47. Miller BJ, Culpepper N. Rapaport MH. C-reactive protein levels in schizophrenia: a review and meta-analysis. Clin Schizophr Relat Psychoses (2014) 7:223-30. doi: 10.3371/CSRP.MICU.020813

48. Stojanovic A, Martorell L, Montalvo I, Ortega L, Monseny R, Vilella E, et al. Increased serum interleukin-6 levels in early stages of psychosis: Associations with at-risk mental states and the severity of psychotic symptoms. Psychoneuroendocrinology (2014) 41:23-32. doi: 10.1016/j.psyneuen. 2013.12.005

49. Khandaker GM, Pearson RM, Zammit S, Lewis G, Jones PB. Association of serum interleukin 6 and C-reactive protein in childhood with depression and 
psychosis in young adult life. JAMA Psychiatry (2014) 71:1121-8. doi: 10.1001/jamapsychiatry.2014.1332

50. Penadés R, García-Rizo C, Bioque M, González-Rodríguez A, Cabrera B, Mezquida $\mathrm{G}$, et al. The search for new biomarkers for cognition in schizophrenia. Schizophr Res Cognit (2015) 2:172-8. doi: 10.1016/j.scog.2015.10.004

51. Blaak EE, Antoine JM, Benton D, Björck I, Bozzetto L, Brouns F, et al. Impact of postprandial glycaemia on health and prevention of disease. Obes Rev (2012) 13:923-84. doi: 10.1111/j.1467-789X.2012.01011.x

52. Kullmann S, Heni M, Hallschmid M, Fritsche A, Preissl H, Häring HU. Brain insulin resistance at the crossroads of metabolic and cognitive disorders in humans. Physiol Rev (2016) 96:1169-209. doi: 10.1152/physrev.00032.2015

53. Lopez Vicchi F, Luque GM, Brie B, Nogueira JP, Garcia Tornadu I, BecuVillalobos D. Dopaminergic drugs in type 2 diabetes and glucose homeostasis. Pharmacol Res (2016) 109:74-80. doi: 10.1016/j.phrs.2015.12.029

54. Nash AI. Crosstalk between insulin and dopamine signaling: A basis for the metabolic effects of antipsychotic drugs. J Chem Neuroanat (2017) 83-84:5968. doi: 10.1016/j.jchemneu.2016.07.010

55. Daws LC, Avison MJ, Robertson SD, Niswender KD, Galli A, Saunders C. Insulin signaling and addiction. Neuropharmacology (2011) 61:1123-8. doi: 10.1016/..neuropharm.2011.02.028

56. ter Horst DM, Schene AH, Figueroa CA, Assies J, Lok A, Bockting CLH, et al. Cortisol, dehydroepiandrosterone sulfate, fatty acids, and their relation in recurrent depression. Psychoneuroendocrinology (2019) 100:203-12. doi: 10.1016/j.psyneuen.2018.10.012

57. Tripathi A, Kar SK, Shukla R. Cognitive deficits in schizophrenia: Understanding the biological correlates and remediation strategies. Clin Psychopharmacol Neurosci (2018) 16:7-17. doi: 10.9758/cpn.2018.16.1.7

58. Pillinger T, Beck K, Gobjila C, Donocik JG, Jauhar S, Howes OD. Impaired glucose homeostasis in first-episode schizophrenia: A systematic review and meta-analysis. JAMA Psychiatry (2017) 74:261-9. doi: 10.1001/ jamapsychiatry.2016.3803

59. Caravaggio F, Hahn M, Nakajima S, Gerretsen P, Remington G, GraffGuerrero A. Reduced insulin-receptor mediated modulation of striatal dopamine release by basal insulin as a possible contributing factor to hyperdopaminergia in schizophrenia. Med Hypotheses (2015) 85:391-6. doi: 10.1016/j.mehy.2015.06.011

60. Galling B, Roldán A, Nielsen RE, Nielsen J, Gerhard T, Carbon M, et al. Type 2 diabetes mellitus in youth exposed to antipsychotics: A systematic review and meta-analysis. JAMA Psychiatry (2016) 73:247-59. doi: 10.1001/ jamapsychiatry.2015.2923

61. Ahmed S, Mahmood Z, Javed A, Hashmi SN, Zerr I, Zafar S, et al. Effect of Metformin on Adult Hippocampal Neurogenesis: Comparison with Donepezil and Links to Cognition. J Mol Neurosci (2017) 62:88-98. doi: 10.1007/s12031-017-0915-z
62. Havelka D, Prikrylova-Kucerova H, Prikryl R, Ceskova E. Cognitive impairment and cortisol levels in first-episode schizophrenia patients. Stress (2016) 19:383-9. doi: 10.1080/10253890.2016.1193146

63. Cameron OG, Thomas B, Tiongco D, Hariharan M, Greden JF. Hypercortisolism in diabetes mellitus. Diabetes Care (1987) 10:662-4. doi: $10.2337 /$ diacare.10.5.662

64. Lee ZSK, Chan JCN, Yeung VTF, Chow CC, Lau MSW, Ko GTC, et al. Plasma insulin, growth hormone, cortisol, and central obesity among young Chinese type 2 diabetic patients. Diabetes Care (1999) 22:1450-357. doi: 10.2337/ diacare.22.9.1450

65. Reynolds RM, Walker BR, Syddall HE, Andrew R, Wood PJ, Whorwood CB, et al. Altered control of cortisol secretion in adult men with low birth weight and cardiovascular risk factors. J Clin Endocrinol Metab (2001) 86:245-50. doi: $10.1210 /$ jcem. 86.1 .7145

66. Liu H, Bravata DM, Cabaccan J, Raff H, Ryzen E. Elevated late-night salivary cortisol levels in elderly male type 2 diabetic veterans. Clin Endocrinol (Oxf) (2005) 63:642-9. doi: 10.1111/j.1365-2265.2005.02395.x

67. Cameron OG, Kronfol Z, Greden JF, Carroll BJ. Hypothalamic-PituitaryAdrenocortical Activity in Patients With Diabetes Mellitus. Arch Gen Psychiatry (1984) 41:1090-5. doi: 10.1001/archpsyc.1983.0179022 0080013

68. Hudson JI, Hudson MS, Rothschild AJ, Vignati L, Schatzberg AF, Melby JC Abnormal Results of Dexamethasone Suppression Tests in Nondepressed Patients With Diabetes Mellitus. Arch Gen Psychiatry (1984) 41:1086-9. doi: 10.1001/archpsyc.1983.01790220076012

69. Stalder T, Kirschbaum C, Kudielka BM, Adam EK, Pruessner JC, Wüst S, et al. Assessment of the cortisol awakening response: Expert consensus guidelines. Psychoneuroendocrinology (2016) 63:414-32. doi: 10.1016/j.psyneuen.2015. 10.010

Conflict of Interest: JL and VS-G have received honoraria for lectures or advisory boards from Jannsen, Otsuka and Lundbeck.

The remaining authors declare that the research was conducted in the absence of any commercial or financial relationships that could be construed as a potential conflict of interest.

Copyright (๑ 2020 Montalvo, González-Rodriguez, Cabezas, Gutiérrez-Zotes, Solé, Algora, Ortega, Martorell, Sánchez-Gistau, Vilella and Labad. This is an open-access article distributed under the terms of the Creative Commons Attribution License (CC $B Y)$. The use, distribution or reproduction in other forums is permitted, provided the original author(s) and the copyright owner(s) are credited and that the original publication in this journal is cited, in accordance with accepted academic practice. No use, distribution or reproduction is permitted which does not comply with these terms. 